\title{
Association between RFC1 A80G polymorphism and the susceptibility to nonsyndromic cleft lip with or without cleft palate: a meta-analysis
}

\author{
Min Sun ${ }^{1,2 \#}$, Cheng Yuan ${ }^{3 \#}$, Jiarong Chen ${ }^{4 \#}$, Xinsheng Gu ${ }^{5}$, Mengyu $\mathrm{Du}^{2}$, Jin Zha ${ }^{2}$, Heng $\mathrm{Li}^{1}$, \\ Dong Huang ${ }^{1}$
}

${ }^{1}$ Department of General Surgery, ${ }^{2}$ Institute of Anesthesiology, Department of Anesthesiology, Taihe Hospital, Hubei University of Medicine, Shiyan 442000, China; ${ }^{3}$ Department of Gynecological Oncology, Zhongnan Hospital, Wuhan University, Wuhan 430071, China; ${ }^{4}$ Department of Oncology, Jiangmen Central Hospital, Affiliated Jiangmen Hospital of Sun Yat-Sen University, Jiangmen 529030, China; ${ }^{5}$ College of Basic Medical Sciences, Hubei University of Medicine, Shiyan 442000, China

Contributions: (I) Conception and design: M Sun, J Chen, J Zha, M Du; (II) Administrative support: None; (III) Provision of study materials or patients: None; (IV) Collection and assembly of data: None; (V) Data analysis and interpretation: M Sun, X Gu, H Li, J Zha; (VI) Manuscript writing: All authors; (VII) Final approval of manuscript: All authors.

"These authors contributed equally to this work.

Correspondence to: Dong Huang. Department of General Surgery, Taihe Hospital, Hubei University of Medicine, Shiyan 442000, China. Email: hd_814@sohu.com.

Background: Reduced folate carrier 1 (RFC1) gene is a candidate for susceptibility to nonsyndromic cleft lip with or without cleft palate (NSCL/P). Association between RFC1 A80G polymorphism and NSCL/P have been studied. The published results are conflicting.

Methods: A meta-analysis of the association between RFC1 A80G polymorphism and NSCL/P was carried out using Stata13.0. A systematic literature search was performed through the PubMed, EMBASE, the Cochrane Library, Web of Science, ScienceDirect, EBSCOhost, China Biology Medicine databases, China National Knowledge Infrastructure and the Wanfang databases. All relevant studies up to 9 September 2019 were identified.

Results: Nine case-control studies including 4,229 total participants (1,334 NSCL/P children, 1,515 healthy children, 656 mothers of the NSCL/P children, and 724 mothers of healthy control children) were included in this study. The meta-analysis revealed that two genetic models of RFC1 A80G polymorphism in NSCL/P children increased risk of NSCL/P: the homozygote model (GG vs. AA, OR =2.346, 95\% CI: $1.127-4.884)$ and the recessive model (GG vs. AG + AA, OR =1.503, 95\% CI: 1.049-2.152). Further sensitivity analysis indicated that the frequency of G allele and GG genotype in NSCL/P children was significantly higher than those in the control. However, there was no significant statistical differences after Bonferroni correction. Subgroup analyses indicated the presence of the association of all the model with NSCL/P risk in the Indian children. RFC1 A80G polymorphism in the maternal population of NSCL/P children was not significantly associated with children NSCL/P.

Conclusions: The RFC1 A80G polymorphism was a candidate for susceptibility to NSCL/P in the Indian pediatric population. More studies with larger samples are necessary to reach more conclusive outcomes.

Keywords: Reduced folate carrier 1 (RFC1); genetic polymorphism; nonsyndromic cleft lip; NSCL/P; meta-analysis

Submitted Feb 04, 2019. Accepted for publication Nov 22, 2019.

doi: $10.21037 /$ atm.2019.12.30

View this article at: http://dx.doi.org/10.21037/atm.2019.12.30 


\section{Introduction}

Nonsyndromic cleft lip with or without cleft palate (NSCL/ $\mathrm{P}$ ), including cleft lip, cleft lip and palate, and cleft palate only (CPO), is a series of disorders affecting the lips and oral cavity (1). NSCL/P is the most common craniofacial malformation with an incidence of approximately 1/700-1,000 live births (2). Being a multifactorial disease, NSCL/P arises as a result of an interplay among remarkably variable factors, such as geographic origin, ethnicity, and socioeconomic status. Several studies have highlighted the role of folate/homocysteine pathway in preventing the risk of NSCL/P during early pregnancy and embryonic development (3), where folic acid and its derivatives play important roles in cell cycle regulation, DNA methylation, homocysteine remethylation, and "one carbon unit" transfer to purines and pyrimidines during DNA biosynthesis (4).

Reduced folate carrier 1 (RFC1) gene is considered a candidate for susceptibility to NSCL/P (1). This gene is also known as the solute carrier family gene 19 (SLC19A1) and mapped into 21q22.2-q22.3. The RFC1 gene encodes an integral membrane protein which delivers the metabolically active form of folate, the 5-methyltetrahydrofolate, into a variety of cells (5). Study by Mossey et al. indicated that RFC1 polymorphisms affected folate metabolism and maternal folate intake (1). The missense variation rs1051266 (A80G) in the exon 2 was proposed as a risk factor for NSCL/P. Conflicting results regarding association between allelic RFC1 A80G polymorphism and NSCL/P in diverse populations have been published $(3,4,6,7)$. Kumari et al. found that RFC1 A80G polymorphism was associated with NSCL/P in the south India (6). Soghani et al. reported that the RFC1 A80G polymorphism was associated with the NSCL/P in Iranian population (8). In this study, we performed a meta-analysis to evaluate current evidence on the relationship between RFC1 A80G polymorphism and NSCL/P in NSCL/P children and their mothers.

\section{Methods}

This study is reported according to "Preferred Reporting Items for Systematic Reviews and Meta-analyses" (PRISMA) guidelines (Figure S1).

\section{Literature search}

A systematic literature search was performed through the PubMed, EMBASE, the Cochrane Library, Web of Science,
ScienceDirect, EBSCOhost, China Biology Medicine disc, China National Knowledge Infrastructure and the Wanfang databases. All relevant studies up to 9 September 2019 were identified. The medical subject headings $(\mathrm{MeSH})$ "cleft lip", "Cleft Palate", "Orofacial Cleft 1", "SLC19A1", "Polymorphism, Single Nucleotide", "Genotype, Alleles", "Genetic Variation", and the free-text words "Harelip", "Orofacial Cleft", "Cleft Lip with or without Cleft Palate", "solute carrier family 19 member 1", "folate transporter 1 ", "IFC-1", " $R F C$ ", "intestinal folate carrier 1", "placental folate transporter", "reduced folate carrier protein", "genetic polymorphism", "genetic", "genetic variant", "genetic variants", "SNP”, "mutation", "variation”, "single nucleotide polymorphism", "variant" were combined in search relevant literature. The full detailed search strategy and searching terms are shown in Table S1. Further, the search spectrum was expanded to the "related articles". All retrieved studies were hand-searched and selected. Authors were contacted when necessary. No language restriction was imposed.

\section{Inclusion and exclusion criteria}

Inclusion criteria: (I) case-control studies evaluating the association between RFC1 A80G polymorphism and NSCL/P; (II) studies with sufficient data for calculating the odds ratios (ORs) and their $95 \%$ confidence intervals (CIs); and (III) studies contained at least two groups (NSCL/P group vs. control group). Exclusion criteria: (I) duplicated studies were removed but the latest article was kept; (II) review articles; (III) editorials or case reports; (IV) animal or cell line studies.

\section{Data extraction}

Two investigators independently and carefully extracted data from all eligible studies into a standard data extraction table in duplicate. If any conflict occurred, a discussion was launched to achieve consensus. The list of items extracted from each study included the name of authors, year of publication, country of author, source of patients, ethnicity, source of controls (population-based or hospital-based controls), matching criteria for controls, number of cases and controls, genotyping method, NSCL/P diagnostic method, genotype distribution of cases and controls, and Hardy-Weinberg equilibrium (HWE) tests in the control group. The authors were contacted for any missing data. 


\section{Quality assessment}

Two investigators independently evaluated the quality of eligible studies using the Newcastle-Ottawa Scale (NOS) (9). If any conflict occurred, a discussion was initiated to achieve consensus.

\section{Data synthesis and analysis}

The meta-analysis was carried out using Stata13.0 (Stata Corporation, College Station, TX, USA). Allele frequencies for the RFC1 A80G polymorphisms from each study were determined by the allele counting method (Table 1). The genotype distributions of controls were used to estimate the frequency of the putative risk allele (80G) using the inverse variance method. A $\chi^{2}$ test determined whether the controls of each study conform to HWE. Meta-analyses were built on the following five genetic models: (I) allele model: G vs. A; (II) heterozygote model: AG vs. AA; (III) homozygote model: GG vs. AA; (IV) the dominant model $(\mathrm{AG}+\mathrm{GG}) v s$. AA; (V) the recessive model GG vs. (AG + AA). Heterogeneity across studies were measured by $\mathrm{I}^{2}$ statistics and $\mathrm{Q}$ tests. When $\mathrm{I}^{2}<40 \%$ and $\mathrm{P}>0.1$, the fixedeffects model was used. On the contrary, $\mathrm{I}^{2} \geq 40 \%$ or $\mathrm{P} \leq 0.1$, the meta-regression analysis was carried out to detect the source of heterogeneity, and stratification analyses were performed according to the outcome of meta-regression analysis. If heterogeneity across subgroup studies $\mathrm{I}^{2}<40 \%$ and $\mathrm{P}>0.1$, the fixed-effects model was applied, otherwise the random-effects model was used. Results are shown as odds ratios (ORs) with $95 \%$ confidence intervals (CIs), with two tailed $\mathrm{P}$ values and statistical significance set at $\mathrm{P}<0.05$. When significant heterogeneity existed, sensitivity analysis was also performed by omitting each study in turn. The sensitivity analyses were conducted by excluding studies not in HWE or not in the population-based (PB) study. The funnel plots, Egger test, and Begg's test were used to assess the publication bias, and $\mathrm{P}<0.05$ was considered significant. The False Discovery Rate (FDR, Benjamini-Hochberg) method and Bonferroni method were applied for multiple comparisons $(10,11)$.

\section{Results}

\section{Selection and characterization of studies}

Our search yielded 248 records, including 19 from PubMed, 17 from EMBASE, 39 from WOS, 145 from ScienceDirect, 27 from EBSCOhost, 3 from CBMdis, 7 from CNKI,
15 from Wanfang Databases. There was no record from the Cochrane Library. After excluding duplicates and irrelevances, we obtained 21 titles and abstracts. Among them, 9 records were deleted as they were reviews and had no numerical data. After further examination of full-text of the remaining 12 studies by two independent reviewers, 2 uncontrolled studies were excluded $(4,12)$, and 2 studies overlapped in subjects $(13,14)$. The article published earlier was excluded (13) and the recently published one was included (14). A detailed flowchart of the selection process is shown in Figure 1.

The major characteristics of the 9 case-control studies (3,5-8,14-17) were summarized in Table 1 , including 4,229 total participants (1,334 NSCL/P children, 1,515 healthy children, 656 mothers of the NSCL/P children and 724 mothers of healthy control children). Two studies were conducted in Asian populations $(14,17)$, 2 in Brazilian populations $(3,7)$ and 5 in Caucasus populations $(5,6,8,15,16)$. In terms of source of controls, 1 study recruited controls from hospital-base population (HB) (16) and 8 from general population-base population (PB) $(3,5-8,14,15,17)$. Two studies demonstrated the affect of maternal folate intake $(14,15)$, and other two studies reported the cleft palate only (CPO) and RFC1 A80G polymorphism $(5,15)$. One study only reported the $\mathrm{AA}$ and GG genotypes in maternal population, ignoring the AG genotype (16). Polymerase chain reaction (PCR) was utilized as the genotyping method in all studies. All 9 studies were of high quality with an NOS score $\geq 6$ (Table S2).

\section{Association between RFC1 A80G polymorphism and NSCL/P risks in the population of children}

The results of meta-analysis of the association between RFC1 A80G polymorphism and NSCL/P risks are summarized in Table 2. The meta-analysis revealed that $\mathrm{NSCL} / \mathrm{P}$ risk was significantly increased in 2 genetic models: GG vs. AA (OR =2.346, 95\% CI: 1.127-4.884), $\mathrm{GG} v s .(\mathrm{AG}+\mathrm{AA})(\mathrm{OR}=1.503,95 \% \mathrm{CI}: 1.049-2.152)$ (Figure 2). However, there was no statistical differences after Bonferroni correction. The meta-regression analysis to identify the source of heterogeneity revealed that it was not deviated in the published year, country, ethnicity, HWE, sample size, NOS score (Table S3). When stratified by country, a significantly increased risk was also found in all 5 genetic models in India (Table 2). When stratified by ethnicity, the recessive model did not exhibit an increased 


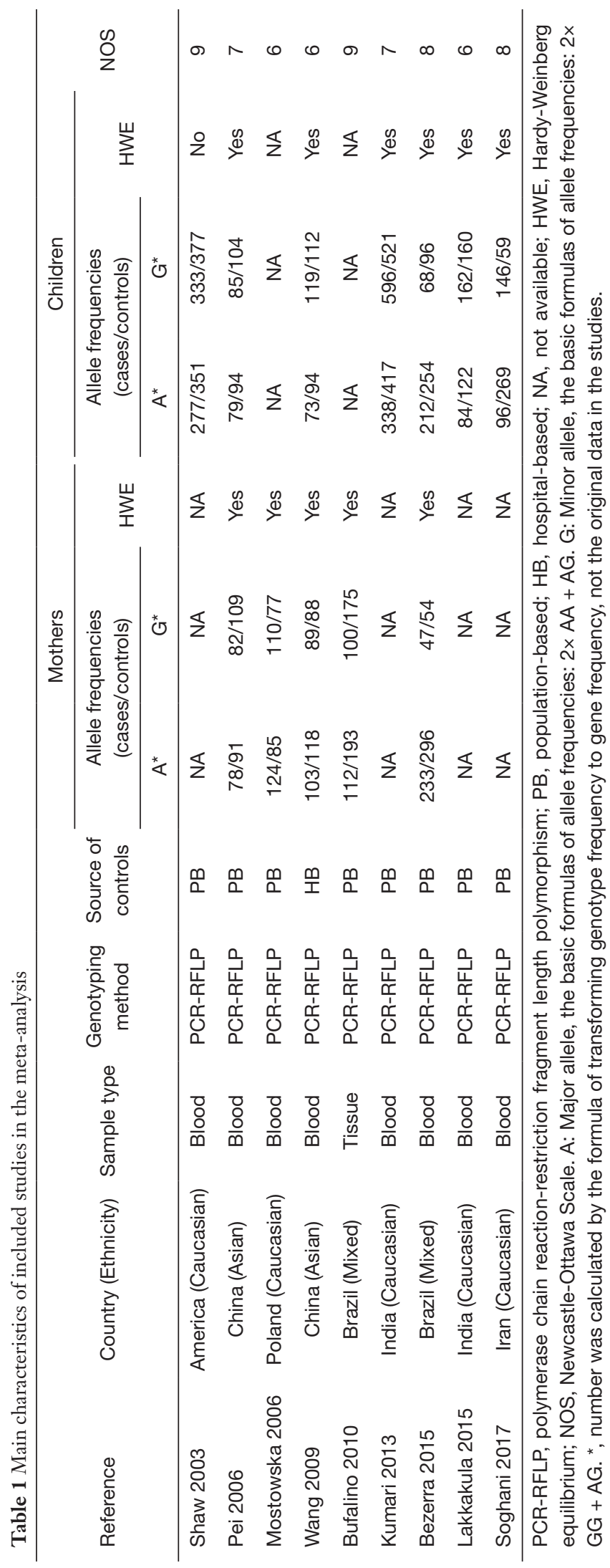

risk in Caucasian population $(\mathrm{OR}=1.890,95 \%$ CI: 1.117 3.197; FDR $=0.045$ with $\mathrm{P}=0.090$ in Bonferroni testing). When stratified by PB or HWE (yes), the recessive model exhibited a significantly increased risk (FDR $=0.005$ with $\mathrm{P}=0.005$ in Bonferroni testing). In the stratified analysis by CPO, maternal folic acid use and maternal folic acid nouse of the children, non-significant associations were found when all studies were pooled with fixed or random-effects models for all these 5 genetic models.

\section{Sensitivity analysis on the association between RFC1 A80G polymorphism and NSCL/P risks in the population of children}

We performed sensitivity analysis by excluding the study by Soghani $e t a l$. because of the outlier data and publication bias (8) (Figure 3). The result showed that the GG genotype frequency (GG vs. AA, GG vs. AG + AA) in the NSCL/P patients were significantly higher than those in the controls (Table 3). The pooled ORs were not qualitatively changed in sensitivity analysis, compared with the overall meta-analysis.

\section{Association between RFC1 A80G polymorphism in the maternal population and susceptibility to NSCL/P in children}

The meta-analysis findings of the association between RFC1 A80G polymorphism in the maternal population and susceptibility to NSCL/P in children were summarized in Table 4. The results showed that all RFC1 A80G genetic models exhibited no significant association in overall comparisons between RFC1 A80G polymorphism in the maternal population and NSCL/P risks in children. In the succeeding stratified subgroup analysis including the Asian subgroup and the Caucasian subgroup, neither did we find any significant association (Table 4). No substantial alterations occurred in results during sensitivity analysis through omitting one study every time, implying the robustness of the results.

\section{Evaluation of publication bias}

None of the studies included in the meta-analysis stated that genotyping was performed blinded to clinical status of the subjects. Funnel plot with egger recursive line seemed symmetric for each genetic model, showing no significant publication bias (Figure 4), which was confirmed with Egger's test in the children and maternal population, 

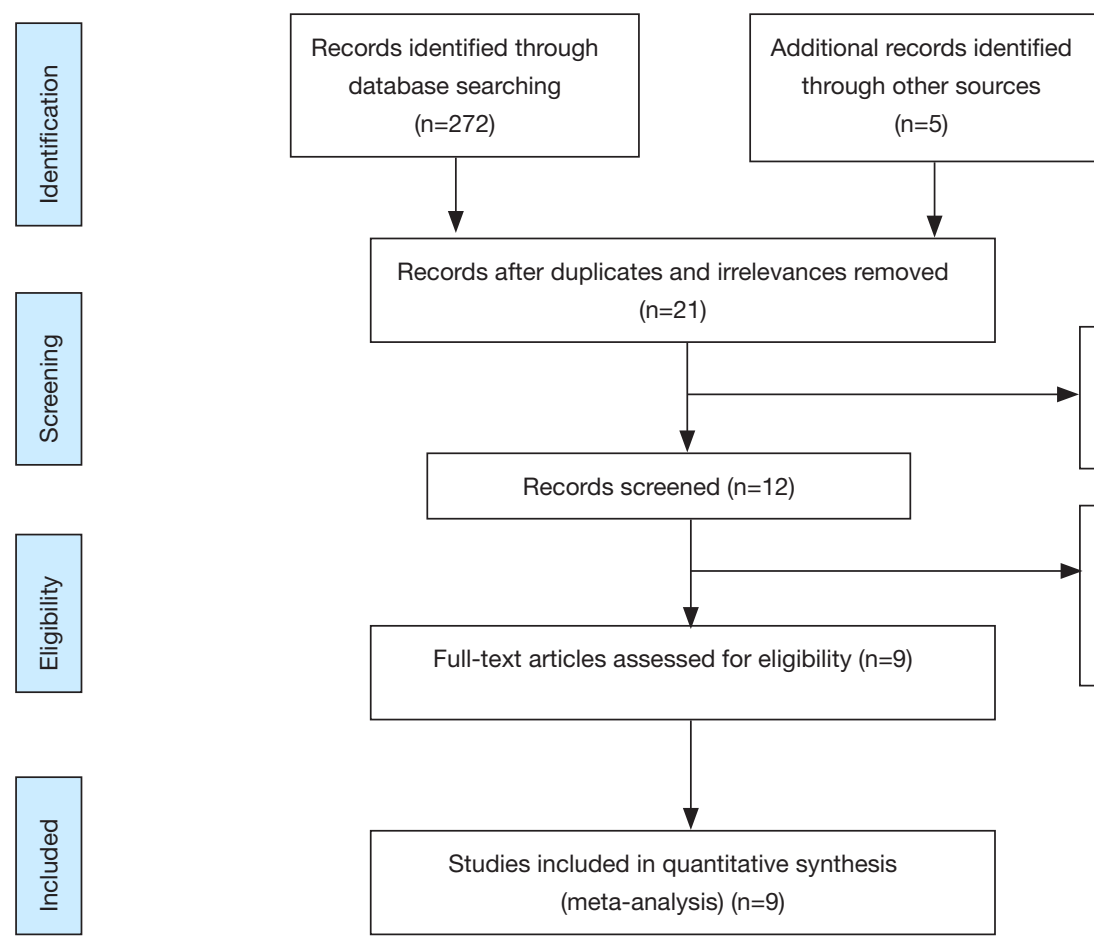

Records excluded, with reasons $(n=9)$

Reviews ( $n=5$ )

No useable numerical data $(n=4)$

Full-text articles excluded, with

reasons $(n=3)$

Duplicate publications $(n=1)$

Uncontrolled study $(n=2)$

Figure 1 Flowchart for selecting studies.

Table 2 Meta-analysis of the association RFC1 A80G polymorphism with risk of cleft lip with or without cleft palate for children

\begin{tabular}{|c|c|c|c|c|c|c|c|c|}
\hline \multirow{2}{*}{ Overall and subgroup } & \multirow{2}{*}{$\begin{array}{l}\text { No. of trials } \\
\text { (participants) }\end{array}$} & \multicolumn{2}{|c|}{ Heterogeneity } & \multirow{2}{*}{ Model } & \multicolumn{2}{|c|}{ Meta-analysis } & \multirow{2}{*}{ Bonferroni } & \multirow{2}{*}{ FDR } \\
\hline & & $\mathrm{P}$ & $\mathrm{I}^{2}(\%)$ & & OR $(95 \% \mathrm{Cl})$ & $P$ for OR & & \\
\hline \multicolumn{9}{|l|}{ Total } \\
\hline AG vs. AA & $7(2,849)$ & $<0.001$ & 90.1 & $\mathrm{R}$ & $1.852(0.944-3.631)$ & 0.073 & 0.365 & 0.073 \\
\hline GG vs. AA & $7(2,849)$ & $<0.001$ & 88.5 & $\mathrm{R}$ & $2.346(1.127-4.884)$ & 0.023 & 0.115 & 0.065 \\
\hline$G G$ vs. $A G+A A$ & $7(2,849)$ & 0.002 & 71.6 & $\mathrm{R}$ & 1.503 (1.049-2.152) & 0.026 & 0.130 & 0.065 \\
\hline \multicolumn{9}{|l|}{ China } \\
\hline G vs. A & $2(380)$ & 0.245 & 25.9 & $\mathrm{~F}$ & 1.159 (0.829-1.619) & 0.310 & 1.00 & 0.485 \\
\hline$A G$ vs. $A A$ & $2(380)$ & 0.338 & 0 & $\mathrm{~F}$ & 1.349 (0.783-2.324) & 0.280 & 1.00 & 0.485 \\
\hline \multicolumn{9}{|l|}{ India } \\
\hline G vs. A & $2(1,200)$ & 0.840 & 0 & $\mathrm{~F}$ & $1.424(1.208-1.678)$ & $<0.001$ & 0.005 & 0.001 \\
\hline AG vs. AA & $2(1,200)$ & 0.257 & 22.3 & $\mathrm{~F}$ & 1.633 (1.163-2.292) & 0.005 & 0.025 & 0.005 \\
\hline GG vs. AA & $2(1,200)$ & 0.756 & 0 & $\mathrm{~F}$ & 2.165 (1.519-3.087) & $<0.001$ & 0.005 & 0.001 \\
\hline$A G+G G$ vs. $A A$ & $2(1,200)$ & 0.425 & 0 & $\mathrm{~F}$ & $1.839(1.331-2.540)$ & $<0.001$ & 0.005 & 0.001 \\
\hline$G G$ vs. $A G+A A$ & $2(1,200)$ & 0.426 & 0 & $\mathrm{~F}$ & 1.489 (1.174-1.889) & 0.001 & 0.005 & 0.001 \\
\hline
\end{tabular}

Table 2 (continued) 
Table 2 (continued)

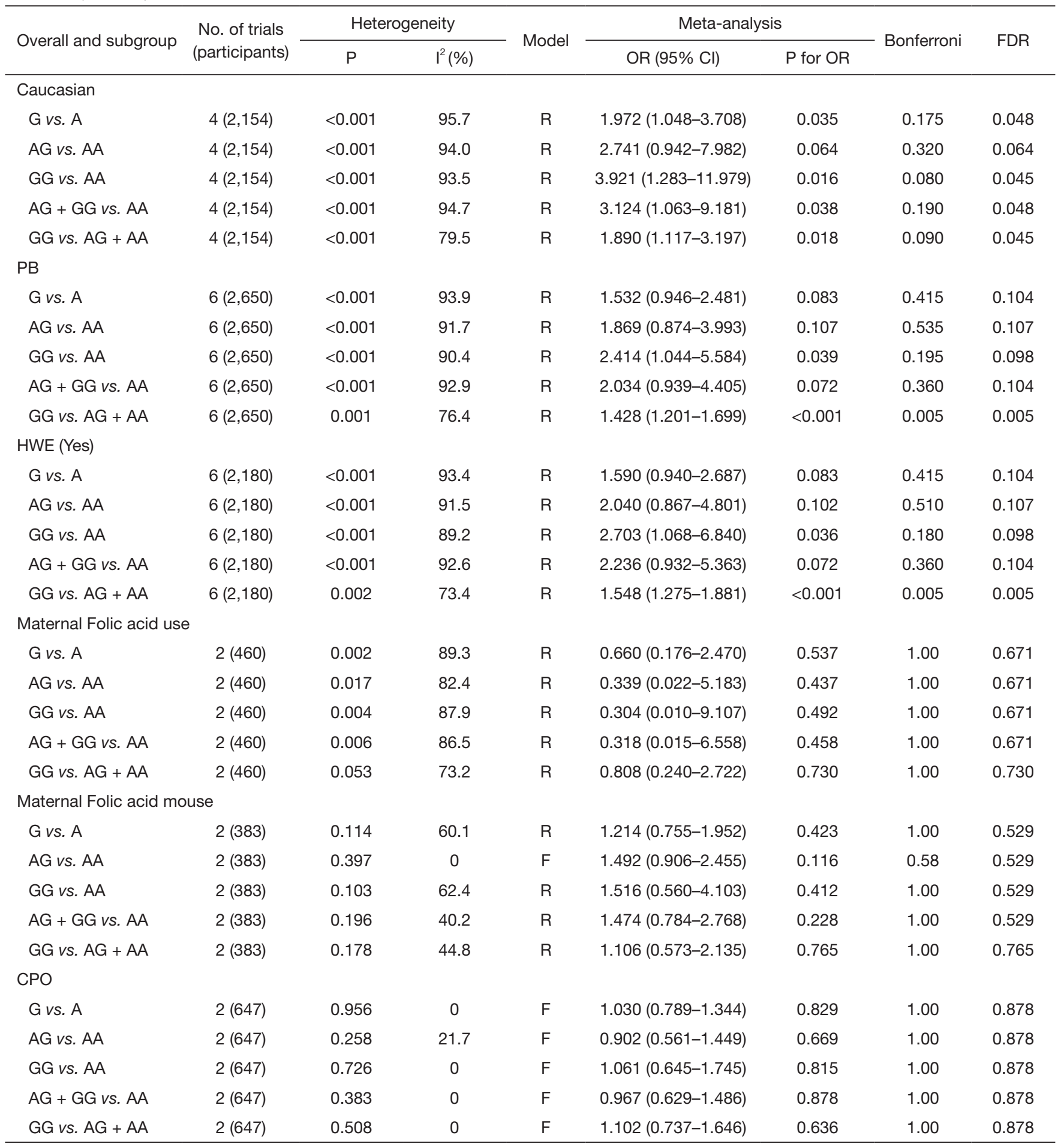

$\mathrm{CPO}$, cleft palate only; $\mathrm{R}$, random; F, fixed. 
A study ID

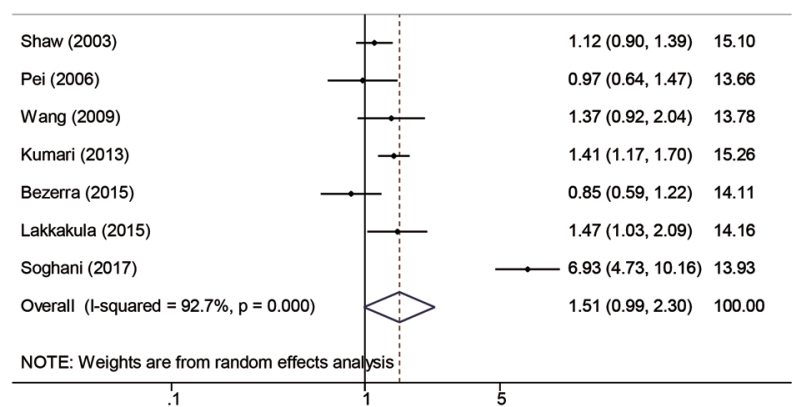

C Study

ID

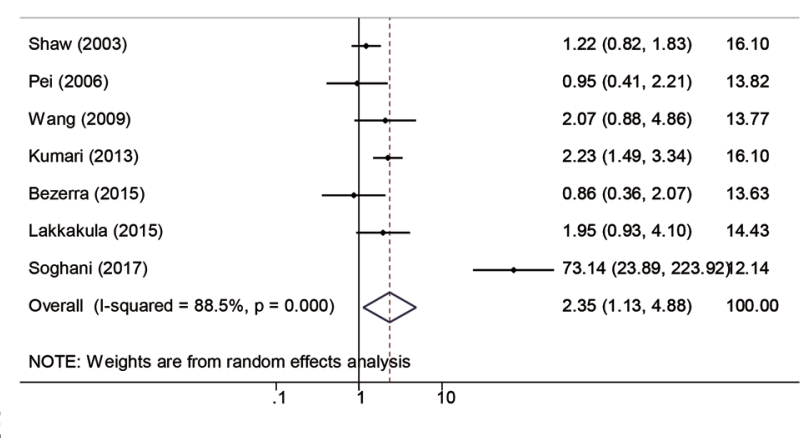

Study

ID

Shaw (2003)

Pei (2006)

Wang (2009)

Kumari (2013)

Bezerra (2015)

Lakkakula (2015)

Soghani (2017)

Overall (I-squared $=71.6 \%, p=0.002$ )

NOTE: Weights are from random effects analysis

NOTE: Weights are from random effects ana|ysis
B

Study

ID

$\%$

OR $(95 \% \mathrm{Cl}) \quad$ Weight

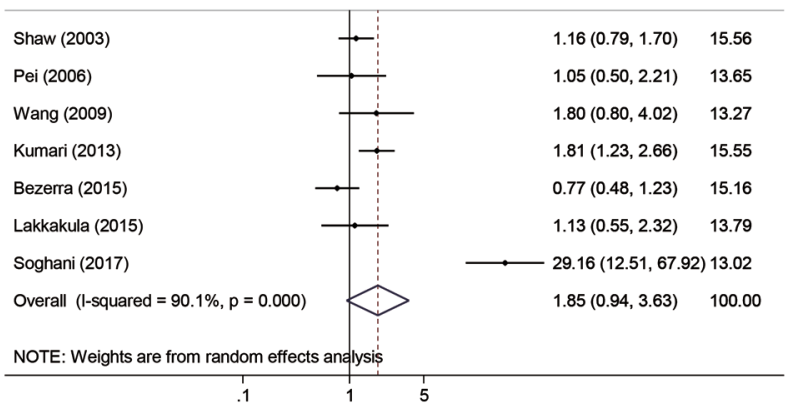

D Study

ID

OR $(95 \% \mathrm{Cl}) \quad$ Weight

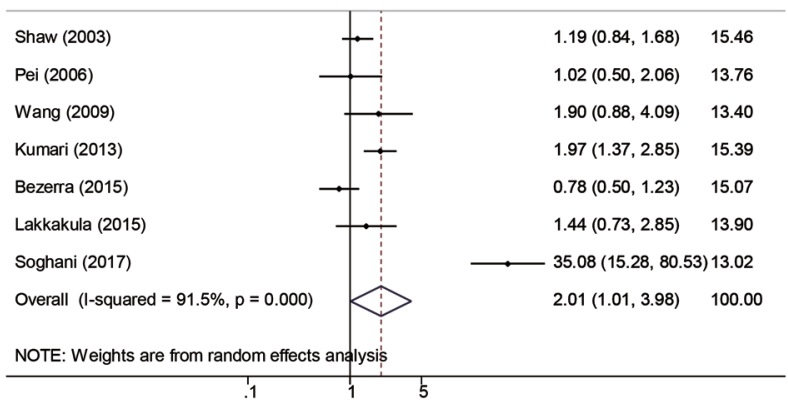

Figure 2 Forest plot of overall analysis in different genetic models. (A) Allele model: G vs. A; (B) heterozygote model: AG vs. AA; (C) homozygote model: GG vs. AA; (D) the dominant model: (AG + GG) vs. AA; (E) the recessive model respectively: GG vs. (AG + AA).

respectively (Table S4).

\section{Discussion}

In recent years, several case-control studies were performed to identify the potential contribution of RFC1 to NSCL/ $\mathrm{P}(3,5-7)$. However, the results are inconclusive. In this study, we investigated association between RFC1 A80G polymorphism and NSCL/P susceptibility using meta- analysis approach based on 9 case-control studies. We found that associations exist between the RFC1 A80G polymorphism and susceptibility to NSCL/P for all the 5 genetic models in pediatric populations of India even with multiple corrections. Subgroups analyses detected a significant association in recessive model for the $\mathrm{PB}$ pediatric population, but no association with Caucasian, Chinese, and Asian (Table 2). Sensitivity analyses showed the results were robust (Table 3). The Funnel plot and the 
A

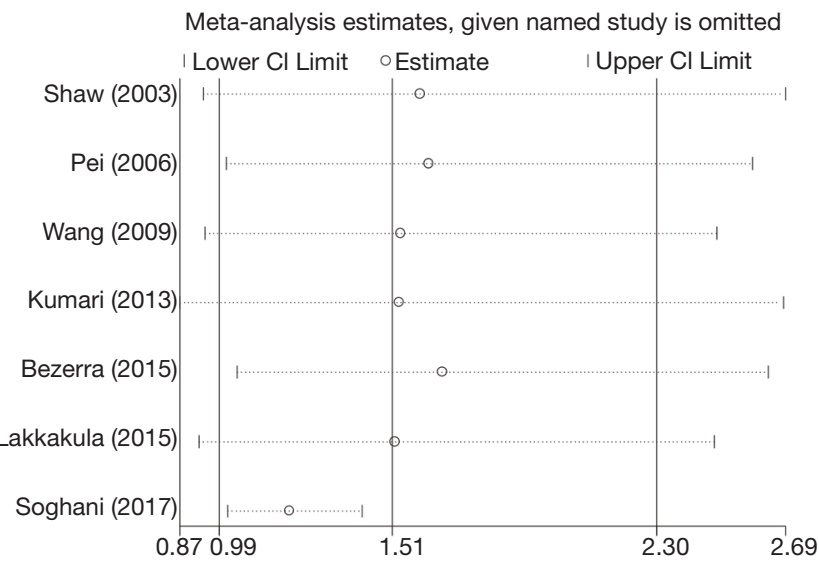

C
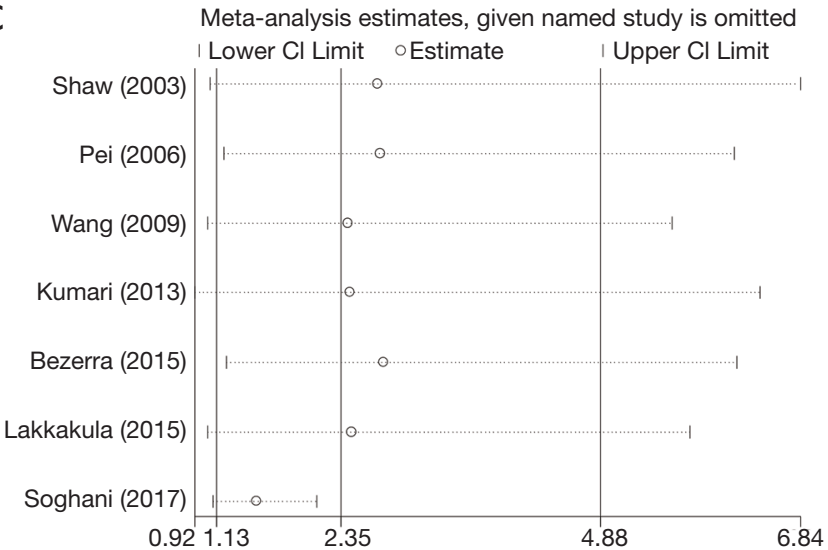

E Meta-analysis estimates, given named study is omitted

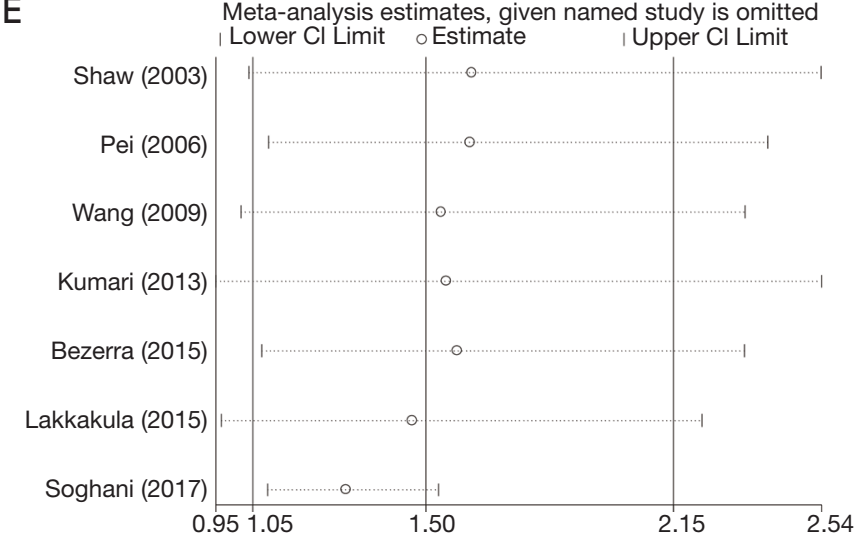

B

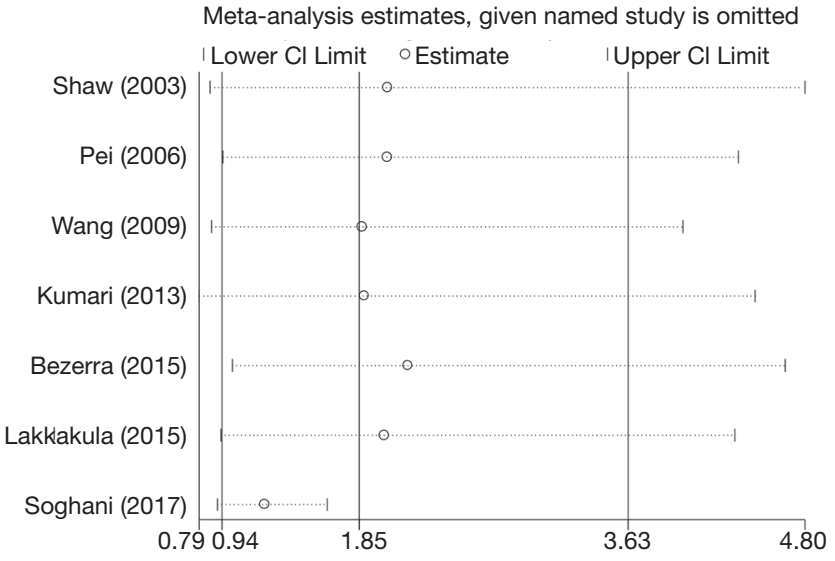

D

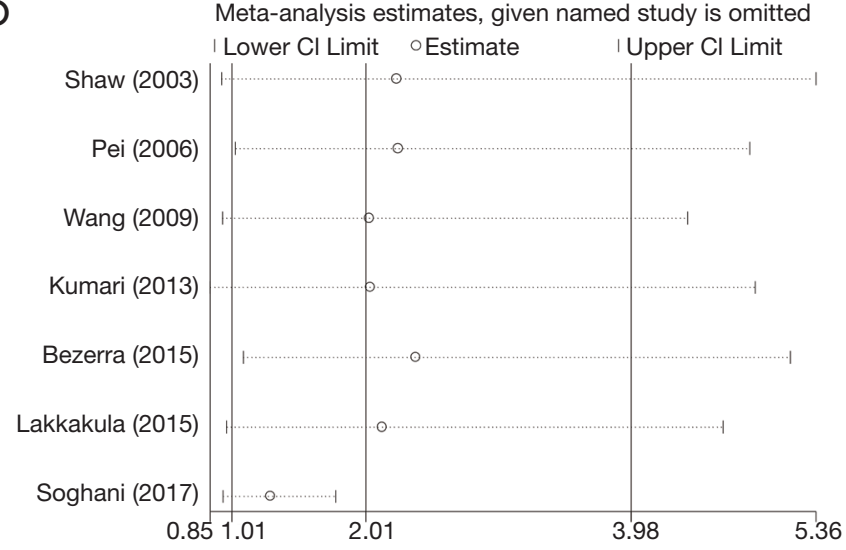

Figure 3 Sensitivity analysis in different genetic models. (A) Allele model: G vs. A; (B) heterozygote model: AG vs. AA; (C) homozygote model: GG vs. AA; (D) the dominant model: (AG + GG) vs. AA; (E) the recessive model respectively: GG vs. (AG + AA).

egger recursive line seemed symmetric for each genetic model, suggesting there was no significant publication bias. Moreover, the results of HWE and source of controls indicated that studies out of HWE and studies with controls from hospital might be the source of bias.

RFC1 mediates delivery of 5-methyltetrahydrofolate into cytoplasm from endocytotic vesicles (18-20), which is one of the few identified mechanisms responsible for internalizing and transporting folate molecules in eukaryotic cells (21). When the concentration of 5-methyltetrahydrofolate is reduced, remethylation of homocysteine into methionine consequently become diminished, and fewer amount 
Table 3 Sensitivity analysis of the association RFC1 A80G polymorphism with risk of cleft lip with or without cleft palate for children

\begin{tabular}{|c|c|c|c|c|c|c|c|c|}
\hline Overall & $\begin{array}{l}\text { No. of trials } \\
\text { (participants) }\end{array}$ & \multicolumn{2}{|c|}{ Heterogeneity } & Model & \multicolumn{2}{|c|}{ Meta-analysis } & Bonferroni & FDR \\
\hline \multicolumn{9}{|c|}{ Children (Children with cleft lip with or without cleft palate) } \\
\hline G vs. A & $6(2,564)$ & 0.094 & 46.9 & $\mathrm{R}$ & $1.198(1.013-1.416)$ & 0.034 & 0.170 & 0.057 \\
\hline$A G$ vs. $A A$ & $6(2,564)$ & 0.116 & 43.3 & $\mathrm{R}$ & $1.225(0.915-1.641)$ & 0.173 & 0.865 & 0.173 \\
\hline$A G+G G$ vs. $A A$ & $6(2,564)$ & 0.040 & 57.0 & $\mathrm{R}$ & $1.299(0.946-1.784)$ & 0.106 & 0.530 & 0.133 \\
\hline$G G$ vs. $A G+A A$ & $6(2,564)$ & 0.508 & 0 & $\mathrm{~F}$ & $1.293(1.088-1.536)$ & 0.003 & 0.015 & 0.008 \\
\hline
\end{tabular}

$\mathrm{CPO}$, cleft palate only; R, random; F, fixed.

Table 4 Meta-analysis of the association RFC1 A80G polymorphism with risk of cleft lip with or without cleft palate for mothers of NSCP/L children

\begin{tabular}{|c|c|c|c|c|c|c|c|c|}
\hline Overall and subgroup & $\begin{array}{l}\text { No. of trials } \\
\text { (participants) }\end{array}$ & \multicolumn{2}{|c|}{ Heterogeneity } & Model & \multicolumn{2}{|c|}{ Meta-analysis } & Bonferroni & FDR \\
\hline \multicolumn{9}{|l|}{ Total } \\
\hline G vs. A & $5(1,380)$ & 0.892 & 0 & $\mathrm{~F}$ & $1.015(0.852-1.209)$ & 0.871 & 1 & 0.937 \\
\hline$A G$ vs. $A A$ & $4(984)$ & 0.352 & 8.3 & $\mathrm{~F}$ & $1.022(0.759-1.375)$ & 0.888 & 1 & 0.937 \\
\hline$A G+G G$ vs. $A A$ & $4(984)$ & 0.504 & 0 & $\mathrm{~F}$ & $1.037(0.781-1.378)$ & 0.800 & 1 & 0.937 \\
\hline$G G$ vs. $A G+A A$ & $4(984)$ & 0.496 & 0 & $\mathrm{~F}$ & $1.015(0.705-1.460)$ & 0.937 & 1 & 0.937 \\
\hline \multicolumn{9}{|l|}{ Caucasian } \\
\hline G vs. A & $3(1,001)$ & 0.898 & 0 & $\mathrm{~F}$ & $1.014(0.813-1.265)$ & 0.901 & 1 & 0.901 \\
\hline$A G+G G$ vs. $A A$ & $2(605)$ & 0.497 & 0 & $\mathrm{~F}$ & $0.935(0.657-1.330)$ & 0.708 & 1 & 0.897 \\
\hline$G G$ vs. $A G+A A$ & $2(605)$ & 0.411 & 0 & $\mathrm{~F}$ & $1.284(0.764-2.159)$ & 0.345 & 1 & 0.897 \\
\hline \multicolumn{9}{|l|}{ Asian } \\
\hline G vs. A & 2 (379) & 0.344 & 0 & $\mathrm{~F}$ & $1.016(0.762-1.353)$ & 0.916 & 1 & 0.964 \\
\hline$A G$ vs. $A A$ & $2(379)$ & 0.435 & 0 & $\mathrm{~F}$ & $1.365(0.830-2.246)$ & 0.220 & 1 & 0.692 \\
\hline GG vs. AA & 2 (379) & 0.435 & 0 & $\mathrm{~F}$ & $0.986(0.528-1.840)$ & 0.964 & 1 & 0.964 \\
\hline$A G+G G$ vs. $A A$ & $2(379)$ & 0.333 & 0 & $\mathrm{~F}$ & $1.256(0.778-2.027)$ & 0.351 & 1 & 0.692 \\
\hline$G G$ vs. $A G+A A$ & $2(379)$ & 0.686 & 0 & $\mathrm{~F}$ & $0.809(0.486-1.346)$ & 0.415 & 1 & 0.692 \\
\hline
\end{tabular}

$F$, the fixed model.

of the methyl group is available for DNA methylation. Hypomethylation can change the transcription and suppression of genes involved in formation of the lip, alveolus, and/or palate. Moreover, RFC1 had been proposed to be an organic anion exchanger in folic acid absorption and transports 5 -methyltetrahydrofolate and thiamine monophosphate bi-directionally $(22,23)$. The RFC1 A80G polymorphism results in the change of amino acid from 

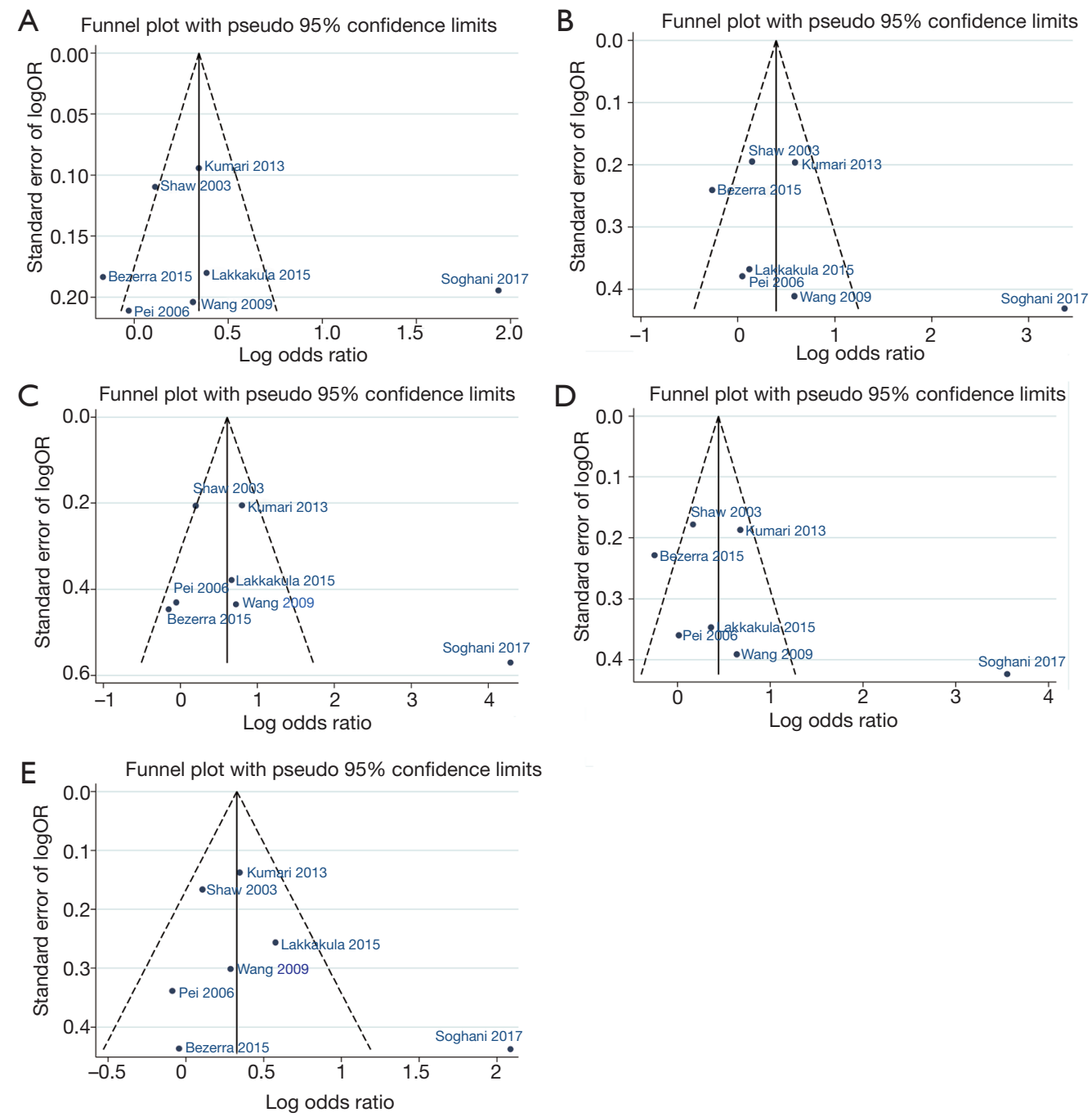

Figure 4 Funnel plot for NSCL/P risk and RFC1 A80G polymorphism in different genetic models. (A) Allele model: G vs. A; (B) heterozygote model: AG vs. AA; (C) homozygote model: GG vs. AA; (D) the dominant model: (AG+GG) vs. AA; (E) the recessive model respectively: GG vs. (AG + AA).

glutamine (encoded by CAG) to arginine (encoded by CGG). The variants of RFC1 may result in lower levels of folate, potentially affecting NSCL/P risk.

The study by van Rooij et al. indicated that maternal periconceptional use of folic acid supplements was an independent preventive factor for NSCL/P (24). Consistent results were also obtained in other studies $(14,15)$. It seems that periconceptional folic acid use may reduce incidence of NSCL/P of the offspring to some certain degree. In this regard, we conducted a subgroup analysis based on maternal intake of folate status in the current study. The results do not support that the association between RFC1 A80G polymorphism and the susceptibility to NSCL/P was affected by maternal folate status and dietary intake (Table 2). On the one hand, the sample size and number of the studies was very small, yielding imprecise risk estimates. On the other hand, study by Ray et al. showed that lowdose folic acid supplementation cannot protect against NSCL/P (25). Further, Tolarova et al. showed that only a very high dose of supplementary folic acid $(10 \mathrm{mg} /$ day) could reduce the risk of NSCL/P significantly (65\% reduction was observed) (26). Meanwhile, study by Crider $e t$ al. suggested that serum/plasma folate concentrations increased $11.6 \%$ (95\% CI: 8.4-14.9) for every $100 \mu \mathrm{g} /$ day folic acid intake basis on regression analysis, and it is generally too late to prevent if folic acid consumption is only initiated after a 
woman learns she is pregnant (27). It seems that maternal serum/plasma folate concentrations decreased the risk for NSCL/P in a dose-dependent manner. Further studies should be carried out to clarify this issue.

In the current study, we also did not observe the association of RFC1 A80G polymorphism with CPO susceptibility from the two studies $(5,15)$. The meta-analysis results didn't support that associations exist between RFC1 A80G polymorphism of maternal populations and susceptibility of children's NSCL/P for all genetic models (Table 4). This may be due to a small quantity of the sample size and number of the studies included in the current study.

Maternal RFC1 genotypes might be more important than those of the infant. Because the mother provides the environment for the embryo of development, the embryo is completely dependent on the mother's folic acid state. We further explored if the risk of delivering a NSCL/P child would increase, when the maternal 80GG genotype was present. It was likely that folic acid supplement use or dietary folate intake were not properly changed by the variants of the RFC1 genotypes in the maternal population.

$\mathrm{NSCL} / \mathrm{P}$ is complex and heterogeneous as shown in its extensive involvement in craniofacial syndromes. Many genes are involved in the development of the primary and secondary palates which may be disrupted by genetic, environmental, or combined factors at any time point during developmental process, leading to NSCL/P. Those are candidate NSCL/P genes, encoding transcription factors (e.g., TBX22, MSX1), growth factors (e.g., TGFA, TGFB3), and adhesion molecules (e.g., PVRL1). More genes causing NSCL/P can be identified by the human genome-wide gene discovery, and positional cloning or positional candidate approaches. In addition, studies investigating the relative risk of NSCL/P contributed by changes of candidate genes such as SNPs can also provide insights into the mechanism of NSCL/P and lead to prevention of NSCL/P.

This meta-analysis was conducted following a canonical systematic process, included 7 case-control studies which confirmed the relationship between RFC1 A80G polymorphism and susceptibility to NSCL/P in children. In addition, the current study does not support the significant association between maternal RFC1 A80G polymorphism and susceptibility to NSCL/P in children based on 5 casecontrol studies. All studies included in the current metaanalysis were of high quality with NOS scores higher than 6, which suggests the data in our analysis is reliable. Our study is the exploratory meta-analysis focusing on the association between RFC1 A80G polymorphism and NSCL/P and
CPO risk. We also considered the influence of maternal folate use status and stratified analysis according to the maternal folate use status, which included more valuable information on this topic. Moreover, we conducted eight subgroup meta-analyses based on characteristics of studies.

Although we have tried our best to retrieve more literatures, some limitations are inevitable. First, moderate heterogeneity was pooled in from some genetic models with the random-effects model. Sensitivity analysis was performed to evaluate the stability of the results. Second, the results of the Egger test and Begg's test demonstrated that the publication biases may not affect the stability of positive results, but more studies are expected to be included in the future to make the results more precise. Additionally, our meta-analysis didn't provide more advisories for the use of folate on prevention, diagnosis, and treatment of maternal NSCL/P.

In conclusion, our results supported that the RFC1 A80G polymorphism is a candidate for susceptibility to NSCL/ $\mathrm{P}$ in the Indian pediatric population, especially for those conformed to the HWE. Because of the heterogeneity of our meta-analysis, a large number of homogeneous studies should be performed to evaluate the results in the future.

\section{Acknowledgments}

Funding: This research was supported by the National Natural Science Foundation of China (81902498), Natural Science Foundation of Hubei Province of China (2019CFB177), Natural Science Foundation of Hubei Provincial Department of Education(Q20182105), Chen Xiao-ping Foundation for the development of science and technology of Hubei Provincial (CXPJJH11800001-2018333), Natural Science Foundation of Hubei Province of China (2016CFB530) and Faculty Development Foundation of Hubei University of Medicine (2014QDJZR01), and National Students' platform for innovation and entrepreneurship training program (201810929005, 201810929009, 201810929068, and 201813249010).

\section{Footnote}

Conflicts of Interest: The authors have no conflicts of interest to declare.

Ethical Statement: The authors are accountable for all aspects of the work in ensuring that questions related 


\section{Page 12 of 13}

to the accuracy or integrity of any part of the work are appropriately investigated and resolved.

\section{References}

1. Mossey PA, Little J, Munger RG, et al. Cleft lip and palate. Lancet;374:1773-85.

2. Sa J, Araujo L, Guimaraes L, et al. Dental anomalies inside the cleft region in individuals with nonsyndromic cleft lip with or without cleft palate. Med Oral Patol Oral Cir Bucal 2016;21:e48-52.

3. Bezerra JF, Oliveira GHM, Soares CD, et al. Genetic and non-genetic factors that increase the risk of nonsyndromic cleft lip and/or palate development. Oral Dis 2015;21:393-9.

4. Girardi A, Martinelli M, Cura F, et al. RFC1 and nonsyndromic cleft lip with or without cleft palate: an association based study in Italy. J Craniomaxillofac Surg 2014;42:1503-5.

5. Lakkakula B, Murthy J, Gurramkonda VB. Relationship between reduced folate carrier gene polymorphism and non-syndromic cleft lip and palate in Indian population. J Matern Fetal Neonatal Med 2015;28:329-32.

6. Kumari P, Ali A, Sukla KK, et al. Lower incidence of nonsyndromic cleft lip with or without cleft palate in females: is homocysteine a factor? J Biosci 2013;38:21-6.

7. Bufalino A, Ribeiro Paranaiba LM, Nascimento de Aquino $\mathrm{S}$, et al. Maternal polymorphisms in folic acid metabolic genes are associated with nonsyndromic cleft lip and/or palate in the Brazilian population. Birth Defects Res A Clin Mol Teratol 2010;88:980-6.

8. Soghani B, Ebadifar A, Khorram Khorshid HR, et al. The study of association between reduced folate carrier 1 (RFC1) polymorphism and non-syndromic cleft lip/palate in Iranian population. Bioimpacts 2017;7:263-8.

9. Stang A. Critical evaluation of the Newcastle-Ottawa scale for the assessment of the quality of nonrandomized studies in meta-analyses. Eur J Epidemiol 2010;25:603-5.

10. Benjamini Y, Drai D, Elmer G, et al. Controlling the false discovery rate in behavior genetics research. Behav Brain Res 2001;125:279-84.

11. Armstrong RA. When to use the Bonferroni correction. Ophthalmic Physiol Opt 2014;34:502-8.

12. Vieira AR, Cooper ME, Marazita ML, et al. Reduced folate carrier 1 (RFC1) is associated with cleft of the lip only. Braz J Med Biol Res 2008;41:689-93.

13. Pei LJ, Ren AG, Hao L, et al. Study on the association between reduced folate carrier gene polymorphism and
Sun et al. RFC1 A80G polymorphism and NSCL/P: a meta-analysis

congenital heart defects and cleft lip with or without cleft palate. Zhonghua Liu Xing Bing Xue Za Zhi 2004;25:1063-7.

14. Pei L, Zhu H, Zhu J, et al. Genetic variation of infant reduced folate carrier (A80G) and risk of orofacial defects and congenital heart defects in China. Ann Epidemiol 2006;16:352-6.

15. Shaw GM, Zhu H, Lammer EJ, et al. Genetic variation of infant reduced folate carrier (A80G) and risk of orofacial and conotruncal heart defects. Am J Epidemiol 2003;158:747-52.

16. Mostowska A, Hozyasz KK, Jagodzinski PP. Maternal MTR genotype contributes to the risk of non-syndromic cleft lip and palate in the Polish population. Clin Genet 2006;69:512-7.

17. Wang Y, Song X, Guo J, et al. Relationship between genetic polymorphisms of RFC1 A80G and nonsymdromic cleft lip with or without palate. Wei Sheng Yan Jiu 2009;38:276-9.

18. Chango A, Emery-Fillon N, de Courcy GP, et al. A polymorphism $(80 \mathrm{G}->\mathrm{A})$ in the reduced folate carrier gene and its associations with folate status and homocysteinemia. Mol Genet Metab 2000;70:310-5.

19. Dixon KH, Lanpher BC, Chiu J, et al. A novel cDNA restores reduced folate carrier activity and methotrexate sensitivity to transport deficient cells. J Biol Chem 1994;269:17-20.

20. Kamen BA, Wang MT, Streckfuss AJ, et al. Delivery of folates to the cytoplasm of MA104 cells is mediated by a surface membrane receptor that recycles. J Biol Chem 1988;263:13602-9.

21. Blanton SH, Henry RR, Yuan Q, et al. Folate pathway and nonsyndromic cleft lip and palate. Birth Defects Res A Clin Mol Teratol 2011;91:50-60.

22. Zhao R, Gao F, Wang Y, et al. Impact of the reduced folate carrier on the accumulation of active thiamin metabolites in murine leukemia cells. J Biol Chem 2001;276:1114-8.

23. Zhao R, Seither R, Brigle KE, et al. Impact of overexpression of the reduced folate carrier (RFC1), an anion exchanger, on concentrative transport in murine L1210 leukemia cells. J Biol Chem 1997;272:21207-12.

24. van Rooij IA, Vermeij-Keers C, Kluijtmans LA, et al. Does the interaction between maternal folate intake and the methylenetetrahydrofolate reductase polymorphisms affect the risk of cleft lip with or without cleft palate? Am J Epidemiol 2003;157:583-91.

25. Ray JG, Meier C, Vermeulen MJ, et al. Association between folic acid food fortification and congenital 
orofacial clefts. J Pediatr 2003;143:805-7.

26. Tolarova M, Harris J. Reduced recurrence of orofacial clefts after periconceptional supplementation with high-dose folic acid and multivitamins. Teratology 1995;51:71-8.

Cite this article as: Sun M, Yuan C, Chen J, Gu X, Du M, Zha J, Li H, Huang D. Association between RFC1 A80G polymorphism and the susceptibility to nonsyndromic cleft lip with or without cleft palate: a meta-analysis. Ann Transl Med 2019;7(23):721. doi: 10.21037/atm.2019.12.30
27. Crider KS, Devine O, Qi YP, et al. Systematic Review and Bayesian Meta-analysis of the Dose-response Relationship between Folic Acid Intake and Changes in Blood

Folate Concentrations. Nutrients 2019. doi: 10.3390/ nu11010071. 
PRISMA 2009 Checklist

\begin{tabular}{|c|c|c|c|}
\hline Section/topic & \# & Checklist item & $\begin{array}{l}\text { Reported on } \\
\text { page \# }\end{array}$ \\
\hline \multicolumn{4}{|l|}{ TITLE } \\
\hline Title & 1 & Identify the report as a systematic review, meta-analysis, or both. & 1 \\
\hline \multicolumn{4}{|l|}{ ABSTRACT } \\
\hline Structured summary & 2 & $\begin{array}{l}\text { Provide a structured summary including, as applicable: background; objectives; data } \\
\text { sources; study eligibility criteria, participants, and interventions; study appraisal and } \\
\text { synthesis methods; results; limitations; conclusions and implications of key findings; } \\
\text { systematic review registration number. }\end{array}$ & 1 \\
\hline \multicolumn{4}{|l|}{ INTRODUCTION } \\
\hline Rationale & 3 & Describe the rationale for the review in the context of what is already known. & 2 \\
\hline Objectives & 4 & $\begin{array}{l}\text { Provide an explicit statement of questions being addressed with reference to } \\
\text { participants, interventions, comparisons, outcomes, and study design (PICOS). }\end{array}$ & 2 \\
\hline \multicolumn{4}{|l|}{ METHODS } \\
\hline Protocol and registration & 5 & $\begin{array}{l}\text { Indicate if a review protocol exists, if and where it can be accessed (e.g., Web } \\
\text { address), and, if available, provide registration information including registration } \\
\text { number. }\end{array}$ & - \\
\hline Eligibility criteria & 6 & $\begin{array}{l}\text { Specify study characteristics (e.g., PICOS, length of follow-up) and report } \\
\text { characteristics (e.g., years considered, language, publication status) used as criteria } \\
\text { for eligibility, giving rationale. }\end{array}$ & 2 \\
\hline Information sources & 7 & $\begin{array}{l}\text { Describe all information sources (e.g., databases with dates of coverage, contact with } \\
\text { study authors to identify additional studies) in the search and date last searched. }\end{array}$ & 2 \\
\hline Search & 8 & $\begin{array}{l}\text { Present full electronic search strategy for at least one database, including any limits } \\
\text { used, such that it could be repeated. }\end{array}$ & Table S1 \\
\hline Study selection & 9 & $\begin{array}{l}\text { State the process for selecting studies (i.e., screening, eligibility, included in systematic } \\
\text { review, and, if applicable, included in the meta-analysis). }\end{array}$ & 2 \\
\hline Data collection process & 10 & $\begin{array}{l}\text { Describe method of data extraction from reports (e.g., piloted forms, independently, in } \\
\text { duplicate) and any processes for obtaining and confirming data from investigators. }\end{array}$ & 2 \\
\hline Data items & 11 & $\begin{array}{l}\text { List and define all variables for which data were sought (e.g., PICOS, funding sources) } \\
\text { and any assumptions and simplifications made. }\end{array}$ & 2 \\
\hline $\begin{array}{l}\text { Risk of bias in individual } \\
\text { studies }\end{array}$ & 12 & $\begin{array}{l}\text { Describe methods used for assessing risk of bias of individual studies (including } \\
\text { specification of whether this was done at the study or outcome level), and how this } \\
\text { information is to be used in any data synthesis. }\end{array}$ & 2 \\
\hline Summary measures & 13 & State the principal summary measures (e.g., risk ratio, difference in means). & 3 \\
\hline Synthesis of results & 14 & $\begin{array}{l}\text { Describe the methods of handling data and combining results of studies, if done, } \\
\left.\text { including measures of consistency (e.g., } I^{2}\right) \text { for each meta-analysis. }\end{array}$ & 3 \\
\hline Risk of bias across studies & 15 & $\begin{array}{l}\text { Specify any assessment of risk of bias that may affect the cumulative evidence (e.g., } \\
\text { publication bias, selective reporting within studies). }\end{array}$ & 3 \\
\hline Additional analyses & 16 & $\begin{array}{l}\text { Describe methods of additional analyses (e.g., sensitivity or subgroup analyses, meta- } \\
\text { regression), if done, indicating which were pre-specified. }\end{array}$ & 3 \\
\hline \multicolumn{4}{|l|}{ RESULTS } \\
\hline Study selection & 17 & $\begin{array}{l}\text { Give numbers of studies screened, assessed for eligibility, and included in the review, } \\
\text { with reasons for exclusions at each stage, ideally with a flow diagram. }\end{array}$ & 3 \\
\hline Study characteristics & 18 & $\begin{array}{l}\text { For each study, present characteristics for which data were extracted (e.g., study size, } \\
\text { PICOS, follow-up period) and provide the citations. }\end{array}$ & 3 \\
\hline Risk of bias within studies & 19 & $\begin{array}{l}\text { Present data on risk of bias of each study and, if available, any outcome level } \\
\text { assessment (see item 12). }\end{array}$ & 3 \\
\hline $\begin{array}{l}\text { Results of individual } \\
\text { studies }\end{array}$ & 20 & $\begin{array}{l}\text { For all outcomes considered (benefits or harms), present, for each study: (a) simple } \\
\text { summary data for each intervention group (b) effect estimates and confidence } \\
\text { intervals, ideally with a forest plot. }\end{array}$ & 4 \\
\hline Synthesis of results & 21 & $\begin{array}{l}\text { Present results of each meta-analysis done, including confidence intervals and } \\
\text { measures of consistency. }\end{array}$ & $\begin{array}{l}4 \\
\text { Table 2-4 }\end{array}$ \\
\hline Risk of bias across studies & 22 & Present results of any assessment of risk of bias across studies (see Item 15). & 5 Table S3-4 \\
\hline Additional analysis & 23 & $\begin{array}{l}\text { Give results of additional analyses, if done (e.g., sensitivity or subgroup analyses, } \\
\text { meta-regression [see Item 16]). }\end{array}$ & 5 \\
\hline \multicolumn{4}{|l|}{ DISCUSSION } \\
\hline Summary of evidence & 24 & $\begin{array}{l}\text { Summarize the main findings including the strength of evidence for each main } \\
\text { outcome; consider their relevance to key groups (e.g., healthcare providers, users, and } \\
\text { policy makers). }\end{array}$ & 6 \\
\hline Limitations & 25 & $\begin{array}{l}\text { Discuss limitations at study and outcome level (e.g., risk of bias), and at review-level } \\
\text { (e.g., incomplete retrieval of identified research, reporting bias). }\end{array}$ & 10 \\
\hline Conclusions & 26 & $\begin{array}{l}\text { Provide a general interpretation of the results in the context of other evidence, and } \\
\text { implications for future research. }\end{array}$ & 11 \\
\hline \multicolumn{4}{|l|}{ FUNDING } \\
\hline Funding & 27 & $\begin{array}{l}\text { Describe sources of funding for the systematic review and other support (e.g., supply } \\
\text { of data); role of funders for the systematic review. }\end{array}$ & 11 \\
\hline
\end{tabular}

From: Moher D, Liberati A, Tetzlaff J, Altman DG, The PRISMA Group (2009). Preferred Reporting Items for Systematic Reviews and MetaAnayses: The PRISMA Statement. PLoS Med 6(6):e1000097. doi:10.1371/journal.pmed1000097

Figure S1 PRISMA checklist. 


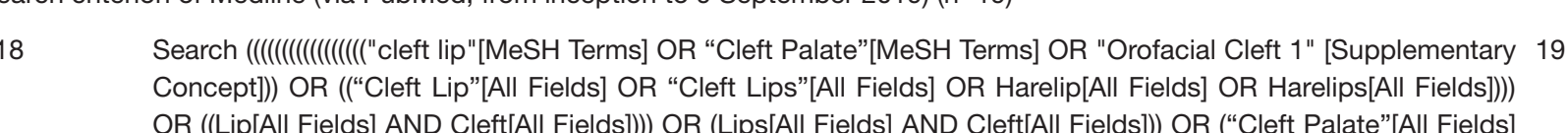

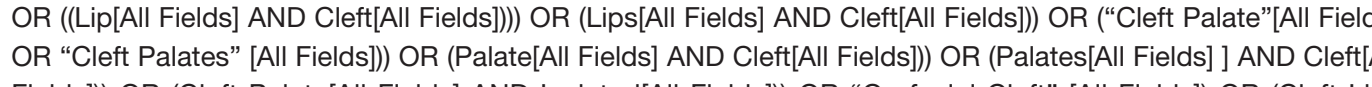

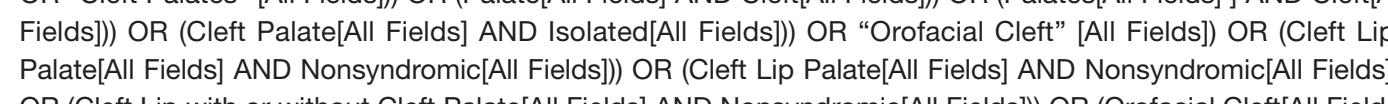

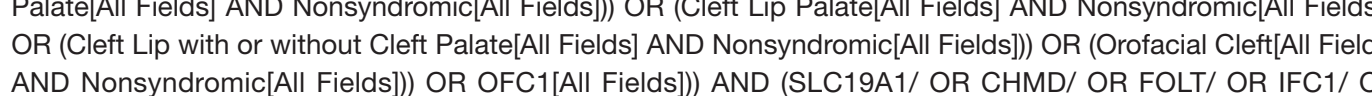

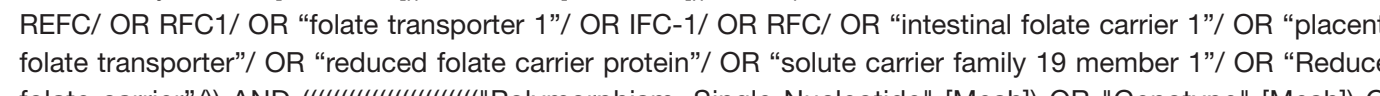

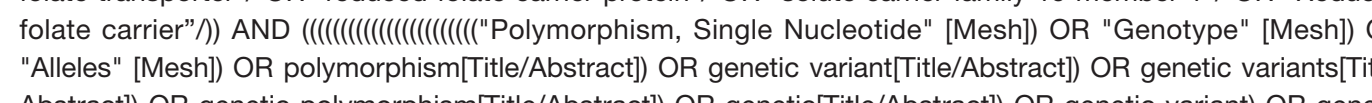

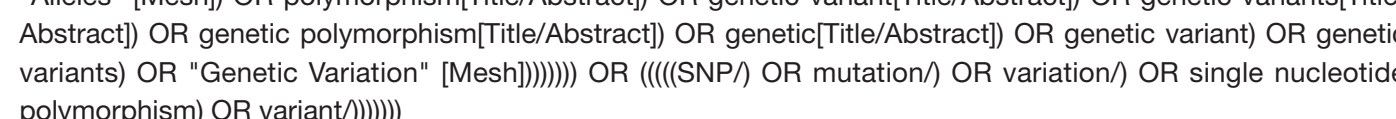

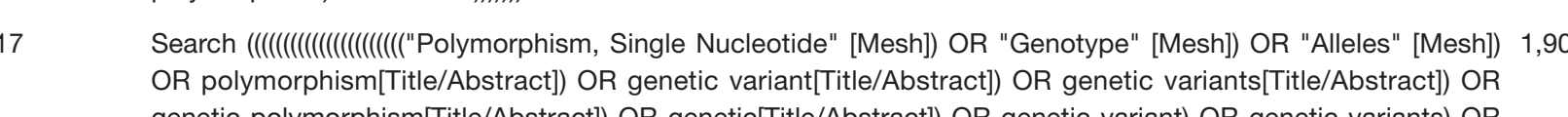

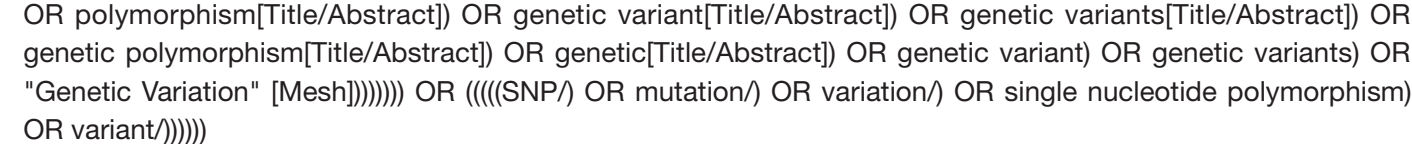

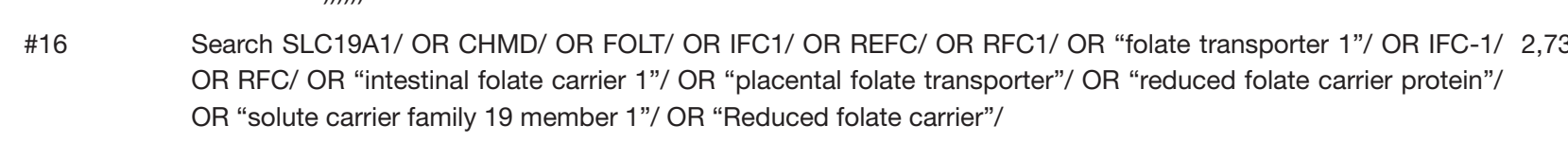

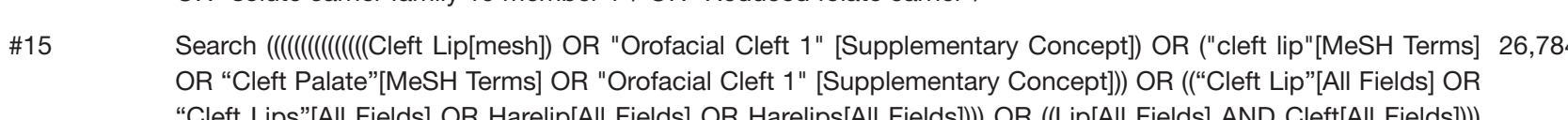

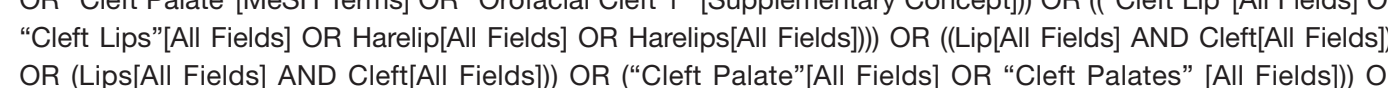

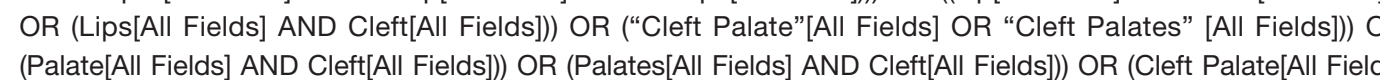

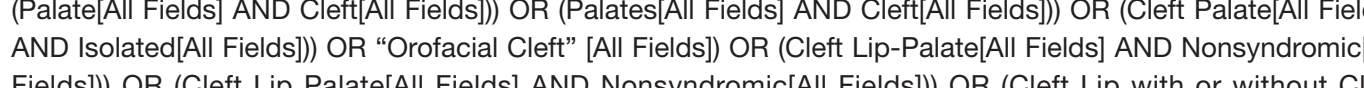

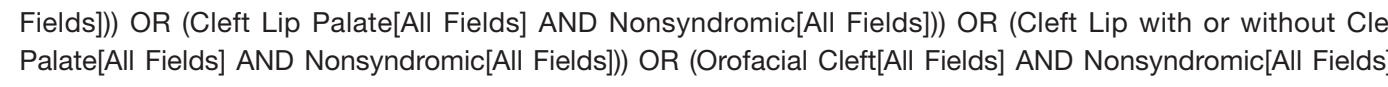
OR OFCT[AII Fields]

\$14 Search OFG(IAAl Fields]

Nonsyndromic[All Fields]

ite[All Fields] AND Nonsyndromic[All Fields]

(a)

Search “Orofacial Clett" [All Fields]

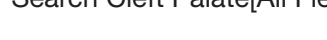

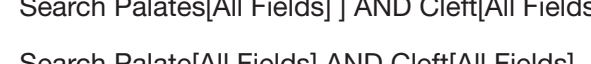

Search "Cleft Palate" "All Fiedds] OR "Clett Palates" "All Fiedss]

Search Lips[Al Fields] AND CleteflAll Fields

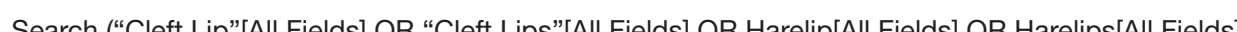
Search criterion of Embase (from 1966 to 9 September 2019) $(n=1$ 1

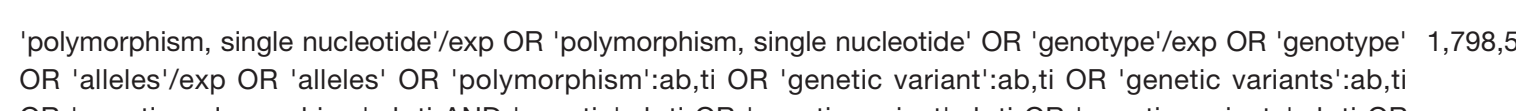

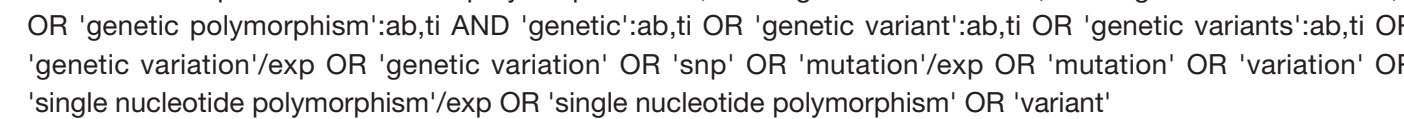

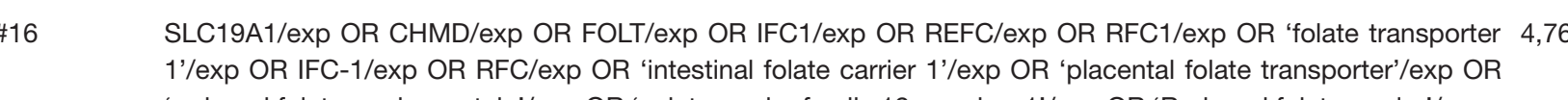

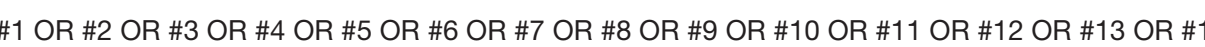

OFC1

Orofacial Cletet AND Nonsyndromic

Cleft Lip with or without Cleff Palate AND Nonsyndromic

Clett LP Palate AND Nonsyndromic

Cleft Lip-Palate

Cleft Palate AND

Cleff Palate AND Isolated

Palate AND Cletf

'Cleft Palate' OR 'Cleft Palates'

Lips AND Clett

(Lip AND Cleft)

('Cleft Lip' OR 'Cleft Lips' OR Harelip OR Hareling

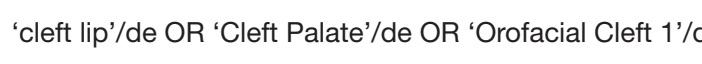

Search criterion of Cochrane Libray (Issue 5 of 12, September 2019) (n=0)

MesH descriptor clett lip

MeSH descripitor Croffacial liett,

Cleft Lip.tiab,kw or Clett Lips:it

Lips.tiab,kw and Clettrtitiab,kw

Palate:t,iab,kw and Clett.t.,ab,kw

Cleft Palatetitiab, ww and Isolatedtitian

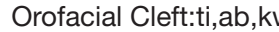

Cleft Lip-Palatetitiab,kw and Nonsyndromictitiab,kw

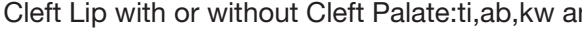

Orofocacial Clettrtiab, kw and Nonsyndromict:tiab

OFCl:tit,ab, kw

MeSS dosesintor PPolymorphism, Single Nucleotidel explode al trees

MesH descriptor: [Alleless] explode all trees

MeSH descripotor: GGenetic Varation] explode all tress

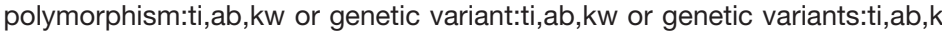

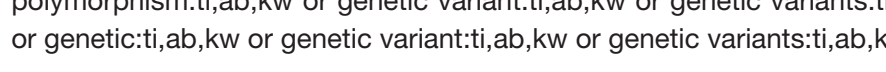

$\# 18$ or $\$ 1$ or $\# 20$ or $\# 21$ or \# 22

MesH descripto

政

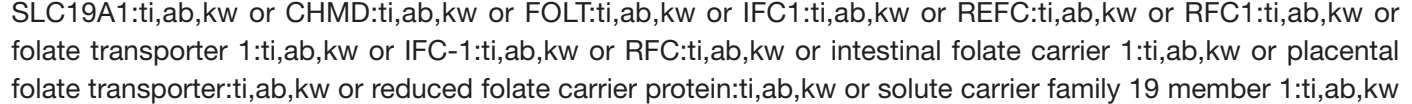

$\begin{array}{ll}\# 27 & \$ 250 \mathrm{or} \$ 26 \\ \$ 22 & \$ 22 \text { and } \$ 22\end{array}$

(Wos) Database (from inception to September 2019)(n=39)

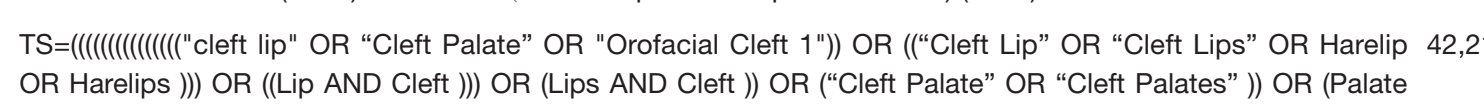

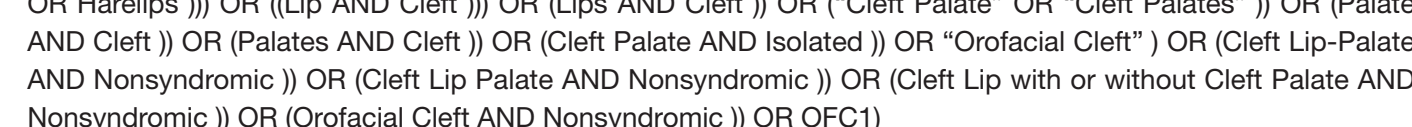

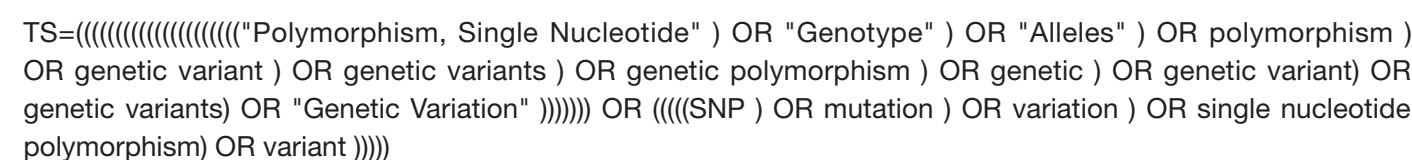

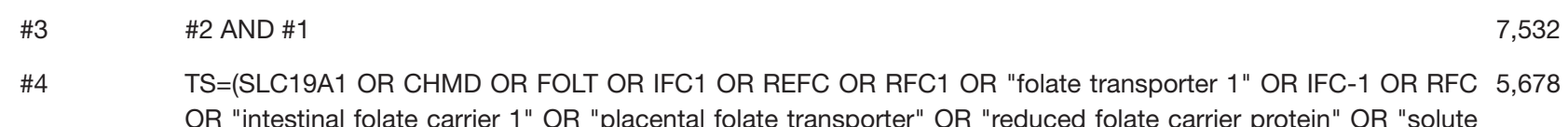

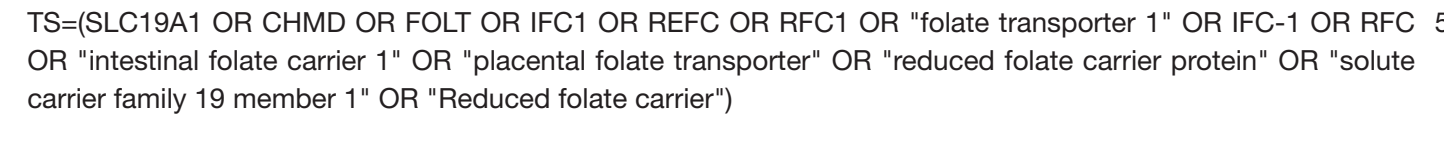
\#5 \#4 AND \#3

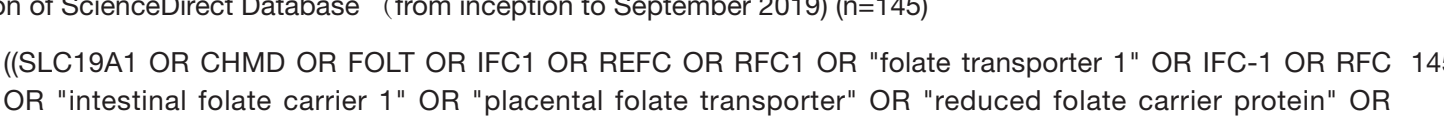

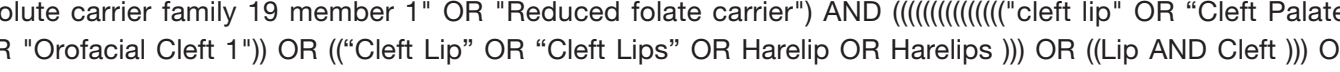

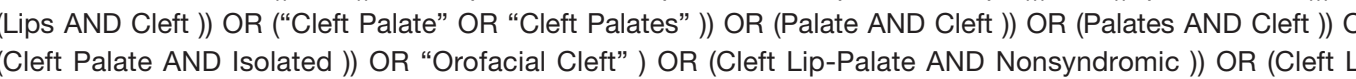
Palate AND Nonsyndromic) ) OR (Cleft Lip with or without Cleft Palate AND Nonsyndromic ) ) OR (Orofotac

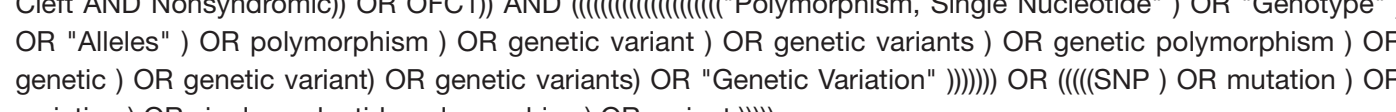
on of EBSCOhost Databases (from incestito to September 2019 ) $(n=27)$

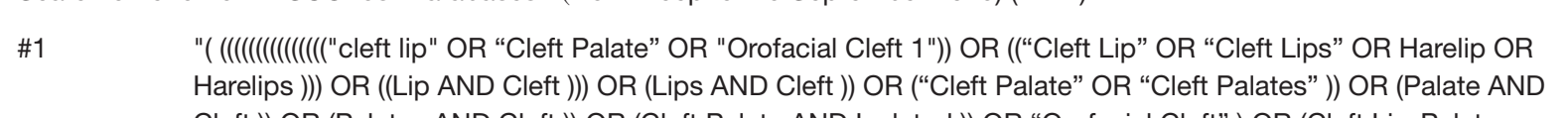

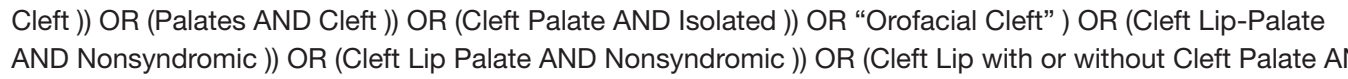

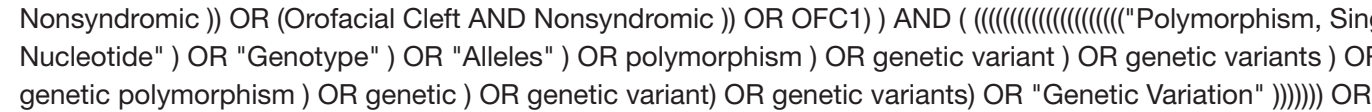

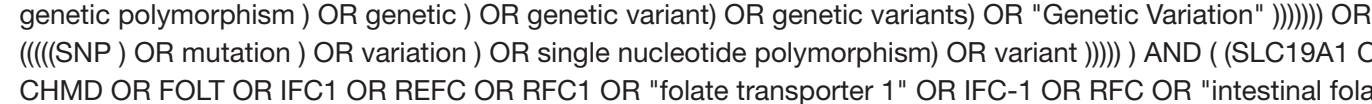

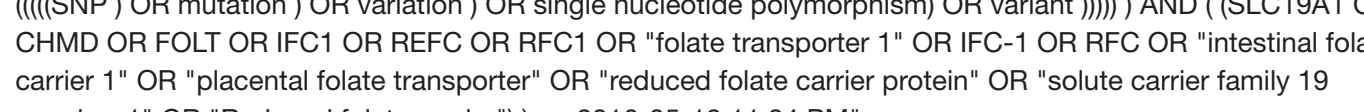


Table S2 Results of quality assessment using the Newcastle-Ottawa Scale for case-control studies

\begin{tabular}{|c|c|c|c|c|c|c|c|c|c|}
\hline \multirow[b]{2}{*}{ Study } & \multicolumn{4}{|c|}{ Selection } & \multirow{2}{*}{$\begin{array}{c}\text { Comparability } \\
\text { Control for } \\
\text { important factor }\end{array}$} & \multicolumn{3}{|c|}{ Exposure } & \multirow[b]{2}{*}{ Scores } \\
\hline & $\begin{array}{l}\text { Adequate } \\
\text { definition of } \\
\text { cases }\end{array}$ & $\begin{array}{l}\text { Representativeness } \\
\text { of the cases }\end{array}$ & $\begin{array}{l}\text { Selection of } \\
\text { controls }\end{array}$ & $\begin{array}{l}\text { Definition of } \\
\text { controls }\end{array}$ & & $\begin{array}{l}\text { Ascertainment } \\
\text { of exposure }\end{array}$ & $\begin{array}{l}\text { Same method of } \\
\text { ascertainment for cases } \\
\text { and controls }\end{array}$ & $\begin{array}{l}\text { Non response } \\
\text { rate }\end{array}$ & \\
\hline Shaw 2003 & is & is & is & $\vec{k}$ & 证败 & 㶦 & is & is & 9 \\
\hline Pei 2006 & 论 & 论 & 论 & - & 论败 & 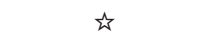 & 论 & - & 7 \\
\hline Mostowska 2006 & 访 & 论 & - & is & is & 弥 & 访 & - & 6 \\
\hline Wang 2009 & 㶦 & 头 & - & 拧 & is & 访 & 头 & - & 6 \\
\hline Bufalino 2010 & 访 & 为 & 头 & 㶦 & 论败 & 㶦 & 为 & 访 & 9 \\
\hline Kumari 2013 & 头 & is & 头 & 㶦 & is & 访 & 访 & - & 7 \\
\hline Bezerra 2015 & is & is & is & is & 论弥 & 访 & is & - & 8 \\
\hline Lakkakula 2015 & 论 & is & 论 & is & - & 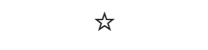 & 论 & - & 6 \\
\hline Soghani 2017 & 访 & 访 & 访 & is & 论弥 & 弥 & 访 & - & 8 \\
\hline
\end{tabular}

a, a maximum of 2 stars can be allotted in this category, one for age, the other for other controlled factors.

Table S3 Meta-regression analysis to detect the source of heterogeneity for the association between RFC1 A80G polymorphism and NSCL/P risks in the population of children

\begin{tabular}{|c|c|c|c|c|c|}
\hline Genetic model & Variables & Coefficient & $95 \% \mathrm{Cl}$ & $P$ & $\mathrm{t}$ \\
\hline \multirow[t]{7}{*}{ G vs. A } & Year & 1.070 & $0.939,1.219$ & 0.239 & 1.34 \\
\hline & Country & 1.332 & $0.868,2.044$ & 0.146 & 1.72 \\
\hline & Ethnicity & 0.984 & $0.305,3.169$ & 0.972 & -0.04 \\
\hline & Source of control & 0.892 & $0.105,7.540$ & 0.896 & -0.14 \\
\hline & NOS score & 1.220 & $0.679,2.194$ & 0.423 & 0.87 \\
\hline & Sample size & 1.000 & $0.997,1.003$ & 0.820 & -0.24 \\
\hline & HWE & 0.704 & $0.090,5.483$ & 0.678 & -0.44 \\
\hline \multirow[t]{7}{*}{ AG vs. AA } & Year & 1.106 & $0.872,1.403$ & 0.324 & 1.09 \\
\hline & Country & 1.579 & $0.722,3.451$ & 0.194 & 1.50 \\
\hline & Ethnicity & 0.900 & $0.119,6.777$ & 0.898 & -0.13 \\
\hline & Source of control & 0.942 & $0.022,39.898$ & 0.969 & -0.04 \\
\hline & NOS score & 1.485 & $0.546,4.040$ & 0.357 & 1.01 \\
\hline & Sample size & 1.000 & $0.995,1.004$ & 0.857 & -0.19 \\
\hline & HWE & 0.564 & $0.016,19.920$ & 0.697 & -0.41 \\
\hline \multirow[t]{7}{*}{ GG vs. $A A$} & Year & 1.158 & $0.880,1.526$ & 0.228 & 1.37 \\
\hline & Country & 1.868 & $0.756,4.617$ & 0.136 & 1.77 \\
\hline & Ethnicity & 1.028 & $0.084,12.559$ & 0.979 & 0.03 \\
\hline & Source of control & 0.821 & $0.008,78.378$ & 0.916 & -0.11 \\
\hline & NOS score & 1.549 & $0.444,5.405$ & 0.409 & 0.90 \\
\hline & Sample size & 1.000 & $0.994,1.005$ & 0.832 & -0.22 \\
\hline & HWE & 0.442 & $0.006,34.083$ & 0.650 & -0.48 \\
\hline \multirow[t]{7}{*}{$G G+A G$ vs. $A A$} & Year & 1.120 & $0.879,1.427$ & 0.282 & 1.21 \\
\hline & Country & 1.636 & $0.735,3.641$ & 0.174 & 1.58 \\
\hline & Ethnicity & 0.926 & $0.113,7.600$ & 0.929 & -0.09 \\
\hline & Source of control & 0.914 & $0.019,44.783$ & 0.955 & -0.06 \\
\hline & NOS score & 1.469 & $0.511,4.225$ & 0.393 & 0.93 \\
\hline & Sample size & 1.000 & $0.995,1.005$ & 0.853 & -0.19 \\
\hline & HWE & 0.525 & $0.013,21.510$ & 0.675 & -0.45 \\
\hline \multirow[t]{7}{*}{$G G$ vs. $A G+A A$} & Year & 1.075 & $0.958,1.206$ & 0.170 & 1.60 \\
\hline & Country & 1.366 & $0.920,2.028$ & 0.098 & 2.03 \\
\hline & Ethnicity & 1.100 & $0.330,3.672$ & 0.847 & 0.20 \\
\hline & Source of control & 0.841 & $0.103,6.892$ & 0.841 & -0.21 \\
\hline & NOS score & 1.176 & $0.648,2.135$ & 0.517 & 0.70 \\
\hline & Sample size & 1.000 & $0.997,1.002$ & 0.780 & -0.29 \\
\hline & HWE & 0.676 & $0.098,4.687$ & 0.626 & -0.52 \\
\hline
\end{tabular}

NOS, Newcastle-Ottawa Scale; HWE, Hardy-Weinberg equilibrium; Source of control, the population source of the control group. 
Table S4 Meta-analysis of the association RFC1 A80G polymorphism with risk of cleft lip with or without cleft palate: publication bias

\begin{tabular}{|c|c|c|c|c|c|}
\hline \multirow{2}{*}{ Genetic model } & \multirow{2}{*}{ Group } & \multirow{2}{*}{ Studies } & \multirow{2}{*}{ Begg's test $(P)$} & \multicolumn{2}{|c|}{ Egger test } \\
\hline & & & & $P$ & $95 \% \mathrm{Cl}$ \\
\hline \multicolumn{6}{|l|}{ Children } \\
\hline G vs. A & Overall & 7 & 0.764 & 0.414 & $(-5.096,10.507)$ \\
\hline$A G$ vs. $A A$ & Overall & 7 & 0.230 & 0.347 & $(-5.716,13.455)$ \\
\hline GG vs. AA & Overall & 7 & 0.764 & 0.414 & $(-5.096,10.507)$ \\
\hline$A G+G G$ vs. $A A$ & Overall & 7 & 0.230 & 0.931 & $(-14.029,15.066)$ \\
\hline$G G$ vs. $A G+A A$ & Overall & 7 & 0.764 & 0.478 & $(-3.264,6.037)$ \\
\hline \multicolumn{6}{|l|}{ Mother } \\
\hline G vs. A & Overall & 5 & 1.000 & 0.861 & $(-9.580,10.802)$ \\
\hline AG vs. AA & Overall & 4 & 0.734 & 0.509 & $(-12.541,18.247)$ \\
\hline GG vs. AA & Overall & 4 & 0.308 & 0.231 & $(-2.490,5.754)$ \\
\hline$A G+G G$ vs. $A A$ & Overall & 4 & 1.000 & 0.567 & $(-11.499,5.808)$ \\
\hline$G G$ vs. $A G+A A$ & Overall & 4 & 0.734 & 0.538 & $(-5.164,7.295)$ \\
\hline
\end{tabular}

